\title{
The typology of motion and posture verbs: A variationist account
}

\author{
Raphael Berthele
}

\author{
Abstract \\ 1. Introduction \\ 2. Typological approaches to motion verbs \\ 3. Data \\ 4. The verb slot: Motion and posture verbs \\ 5. The verb-sister slot: Path and place arguments \\ 6. Conclusions
}

According to work by Talmy, Slobin and others, satellite-framed (S)-languages tend to express the path of motion in a verb particle and the manner of motion in the verb (jump, run, etc.), whereas verb-framed (V)-languages express the path in the verb (enter, exit) and the manner in an adverbial - if at all. In this paper, this typological distinction will be applied to data from Swiss German (Muotathal dialect), Standard German and French. As expected, French narratives use more path verbs than German narratives. However, there are surprising differences within the S-framed German varieties: Muotathal dialect rarely expresses manner, in some cases even less frequently than French. It is argued that two typological categories are not sufficient once dialects are taken into account. The categories not only need to be refined. It also needs to be recognized that there are additional dimensions (e.g. orality/literacy) which are important factors affecting typological affiliations.

\section{Introduction}

In the present contribution, issues from the typological research on motion verbs are carried into the domain of variationist/dialectological linguistics. Three sets of parallel data are analyzed and compared here: Swiss German (SG) dialect data (from the Muotathal area in central Switzerland, MU) and Standard High German (SHG) data are compared with standard French (FR) data. The main aim is twofold: first, it will be shown that the assimilation of theoretical frameworks in typology (and - since they are tightly connected - with frameworks in psycholinguistics and cognitive linguistics) can lead to new dialectological insights. As will be shown, the former can in particular shed some new light on 'hidden' or at least non-salient differences between dialects and their corresponding standard languages. Second, this contribution will argue that certain categories and distinctions that have sometimes been taken for granted in typology and cognitive linguistics have to be fundamentally revised if one takes into account dialectological and variationist data.

In section 2, some of the main issues of 'motion verb research' in typological and cognitive linguistics will be addressed. Section 3 presents the data sample used in this contribution, as well as some necessary notes on the sociolinguistics of Swiss German. Section 4 then singles out the verb slot and shows different usage patterns of the 'manner' and 'displacement' verbs in the varieties used in this paper. In section 5, the path and place arguments in the verb-sister position are compared, followed by a demonstration of the sometimes striking differences in the linguistic overtness of spatial information. These analyses, finally, are taken as the basis of a detailed discussion of the typological assumptions and what, in the case of this particular domain, dialectologists and typologists can learn from each other (section 6).

\section{Typological approaches to motion verbs}

As Tesnière (1959: 307-308) has pointed out, verbs used in constructions referring to moving objects in space can be categorized into two groups, which he calls movement and displacement. The former are verbs such as French marcher, courir, trotter, galoper, sauter, sautiller, ramper, voler, nager; i.e. verbs which, according to Tesnière, express the somatic conditions of the moving object. Displacement verbs, on the other hand, express concepts tied to the spatial ground on which the motion takes place (examples: monter, descendre, aller, venir, entrer, sortir). It has long been observed that the languages of the world do not all pay the same amount of attention to these two 
types of verbs. Among the scholars working on this phenomenon, Talmy (1985, 2000b: 213-288) has probably been the most influential. Slobin in particular (1991; 1996; forthcoming]; Slobin and Bocaz 1988) has used Talmy's framework for the crosslinguistic comparison of spatial expressions (mainly motion verbs) and their acquisition. Given the considerable resonance of Talmy's and Slobin's work, this paper will use Talmy's conceptual and terminological framework in order to analyze dialectal and standard language data. It is thus necessary to provide a short introduction into the basic categories and distinctions made by Talmy and the scholars who build upon his ideas.

According to Talmy, the conceptualization of a motion event (and, as we will see in a moment, of static spatial settings as well) can be analyzed as integrating a series of different conceptual components. In Figure 1, two instances of locating expressions and their conceptual components are presented.

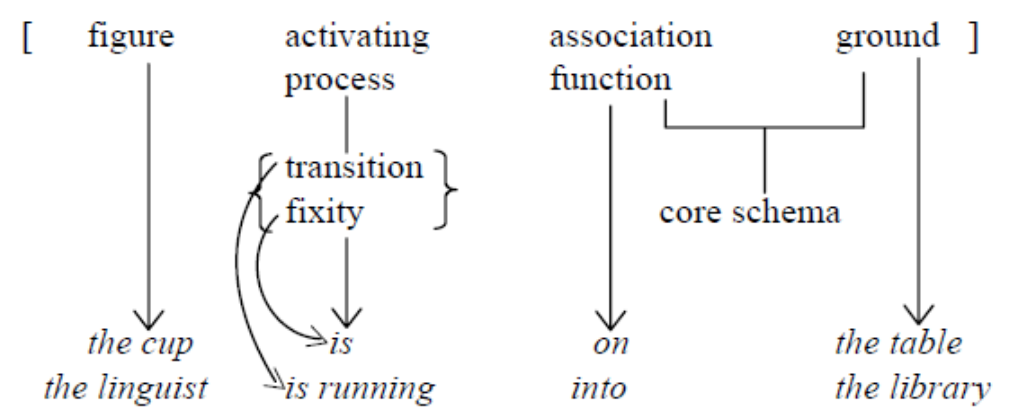

Figure 1. Conceptual structure of a locating expression (adapted from Talmy 2000b: 221)

The entity on which the attention in discourse is predominantly centered is called the figure. This is the object or being which is going to be located or traced in space. The figure is typically expressed in the subject NP of a spatial expression, as illustrated in Figure 1. The second conceptual part of a motion event is the activating process. It can have two distinct parameter settings, either transition or fixity. Despite the fact that Talmy himself uses the term 'motion events' (2000b: 226) for all instances covered by the conceptual content rendered in Figure 1, I consider it to be more appropriate to use a more generic and less 'dynamic' term, namely spatial localization event. The activating process is generally mapped onto the verb, if the conceptual content is linguistically expressed.

The third conceptual entity in Talmy's framework is the association function, which relates the figure to its spatial environment. In the examples in Figure 1, the association function is expressed in the preposition (P) of the linguistic expression. The last entity, the ground, is (part of) the spatial environment in respect to which the figure is either statically located or moving. Since the conceptual core of any spatial localization event is by definition the localization of a figure with respect to the ground, the association function together with the ground can be seen as the core schema of the whole conceptualization. In some cases, however, the association function alone can be seen as the core schema, particularly in utterances which do not openly specify the ground (e.g. The boy fell down [from the tree].)

As we have seen in Figure 1, the verb carries the concept of transition/fixity. In the second example in Figure 1, however, the verb not only encodes motion, but it adds information about the nature of the motion. The verb run thus is an instance of Tesnière's mouvement. Talmy analyses these verbs as integrating two components, namely [motion] and [manner (of motion)]. This is one instance of the more general phenomenon of integrating more than one event into a single clause (Talmy 2000b: 214-216). The other type of event integration which is important for spatial expressions is the integration of motion and path, i.e. the co-integration of the association function into the verb. Figure 2 depicts the enhanced mapping of conceptual content into syntactic constituents. 


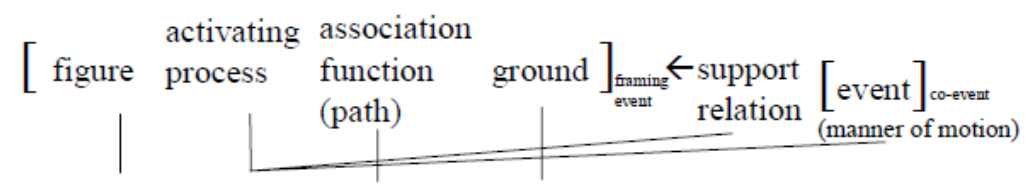

the linguist is running into the library

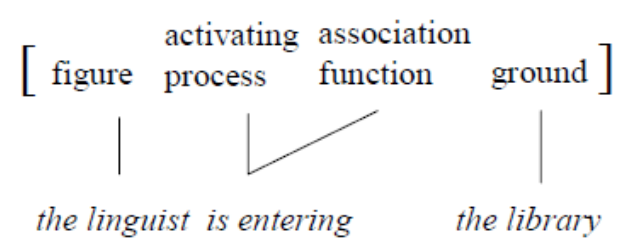

Figure 2. Co-event (=manner) integration and path verbs

In the first example in Figure 2, information about the manner of motion (an example of what Talmy calls a co-event) is mapped onto the verb. In the second example, the association function (=the path) is mapped onto the verb. According to Talmy, the languages of the world show different patterns of conceptual mappings in the verb slot. For the present purposes, it is sufficient to distinguish two groups: either the languages tend to integrate a co-event in the verb slot, or they tend to integrate the association function into the verb slot (Talmy 2000b: 223). If the association function is not mapped to the verb slot, it is expressed in a constituent which stands in a sister position to the verb: either a satellite or a PP. A satellite is a particle such as the German separable and inseparable verb-prefixes ("Präfixe und Halbpräfixe", cf. Eisenberg et al. 1998: 435). If, in a VP, a satellite occurs alone, there is no explicit ground element in the surface structure. The ground then can easily be inferred from the (textual) context. Depending on this difference of lexicalization patterns, Talmy proposes to distinguish between satellite-framed (S-) languages and verb-framed (V-) languages:

Languages that characteristically map the core schema into the verb will be said to have a framing verb and to be verb-framed languages. Included among such languages are Romance, Semitic, [...]. On the other hand, languages that characteristically map the core schema onto the satellite will be said to have a framing satellite and to be satellite-framed languages. (Talmy 2000b: 222)

According to Talmy and Slobin (1991, 1996), there are important differences between S- and V-languages in the realm of motion events. S-languages (e.g. English, German) express the core schema of the spatial relation, generally the path of a moving entity, in a particle, whereas V-languages (e.g. Spanish, French) map the core schema onto the verb. Since the verb slot in S-languages is available for additional information, they tend to integrate co-events in their expressions, mainly the manner of motion of the figure. As Slobin (1996: 218) shows convincingly, these lexicalization patterns contribute to typical "typologies of rhetoric", i.e. the speakers of a particular language tend to tell different stories, depending on whether their language is of the S- or V-type. As an example, Slobin (1996) has been able to show that English displays a higher degree of manner-saliency than Spanish, a V-language: Spanish narratives use many fewer manner-specifying verbs when describing moving figures in space; the verb inventory as a whole is smaller than the one used by English speakers. The English and Spanish examples (1) and (2) represent this difference; both describe exactly the same picture from the Frog Story (Mayer 1969; examples are taken from Slobin, forthcoming):

(1) the boy tumbles down from the branch

(2) y el niño se cae 
The satellite-framed languages in our sample also tend towards greater specification of manner, probably because the lexicon provides a large collection of verbs that conflate manner with change of location (crawl, swoop, tumble, etc.), often conflating cause as well (dump, hurl, shove, etc.). In verb-framed languages, such elaboration is more of a "luxury", since path and manner are elaborated in separate expressions, which are generally optional, and which are less compact in form [e.g., 'exit flying (from the hole)' vs. 'fly out (of the hole)']. As a consequence of these differences, it seems - at least in our data - that English and German narrations are characterized by a great deal of dynamic path an manner description, while Spanish, Hebrew, and Turkish narrations are less elaborated in this regard, but are often more elaborated in description of locations of protagonists and objects and of endstates of motion. (Berman and Slobin 1994: 118-119)

There is no doubt that, rather than applying a rigid binary distinction, the languages of the world can be positioned on a cline of manner saliency, with (proto)typical V-languages on one end and typical S-languages on the other end of the scale (Slobin, forthcoming).

The list of languages which are analyzed using the 'Talmy-Slobin' paradigm is considerable (cf. the extensive list of Frog Story studies in the Appendix of Strömqvist and Verhoeven, forthcoming). However, I am not aware of systematic research on the relationship between dialects and their corresponding standard languages. And this, of course, is what the analysis in the present contribution aims at.

Before we can proceed to the analysis of the French and German data, one additional theoretical approach has to be discussed briefly. In his (2001) paper, Wälchli proposes a more fine-grained typology of motion verbs; more precisely, he focuses on a typology of displacement, in the sense introduced by Tesnière (see above). First, we can distinguish three different 'loci' of the expression of displacement: “(V) Verbal encoding (i.e. by the verb stem), (AN) adnominal encoding (i.e. by prepositions, postpositions or case marking), and (AV) adverbal encoding (i.e. by verb affixes or verb particles).” (Wälchli 2001: 301)

Wälchli's verbal encoding is thus the predominant lexicalization pattern in typical V-languages, and the two other categories (AN, AV) are the loci of the core schema in S-languages. An innovative aspect of Wälchli's proposal is his subcategorization of the different types of path. He proposes 6 "cardinal kinds of displacement", which he labels with the help of Latin prepositions: AD, IN, SUPER, AB, EX, DE (cf. Table 1). Based on a corpus of parallel texts (the Gospel according to Mark), 40 languages are analyzed, and the coding of path in what Wälchli calls "basic intransitive motion" (2001: 300), i.e. motion "of humans (not animals or objects) moving without special haste and without vehicles", is analyzed. One main result of this study is a cross-tabulation of the languages in Wälchli's sample, based on the number of path distinctions made in the adnominal and in the verbal slot. Typical S-languages are those which show up to 6 adnominal distinctions (e.g. Western Apache, Russian), whereas typical V-languages offer up to 6 verbal distinctions but only very few adnominal distinctions (e.g. Tagalog, Kiswahili). This cross-tabulation allows for a two-dimensional representation of the path expression, and in particular it shows that some languages employ both verbal and adnominal encoding of the path (Udmurt, Erzya Mordvin). Whereas this representation allows us to draw a more adequate picture of the locus of expression of path, it is - and Wälchli is, of course, perfectly aware of that - based on a problematic text corpus and focuses on only one particular type of displacement

Wälchli's list of cardinal paths proves to be helpful not only for the typological comparison of a great number of genetically different languages, but also for our present purposes. However, there are two aspects in Wälchli's list of cardinal paths which need some modification in order to match the needs of the present analysis. Firstly, in Wächli's list, displacement along the vertical axis is conflated with a specified movement away or towards a ground element. E.g., as Table 1 shows, downward movement coincides with movement away from the source. This association is an unnecessary constraint for the analysis of the data here, since a motion verb coding a downward path can open a slot for either the source (3) or the goal (4) or even both source and ground objects (5), as the French examples below show clearly:

(3) le garçon tombe de l’arbre

'the boy falls from the tree'

(4) le garçon tombe sur le sol

'the boy falls onto the ground'

(5) le garçon tombe de l'arbre sur le sol

'the boy falls from the tree onto the ground' 
Thus, I propose to categorize the cardinal paths in a more general manner, not specifying for source or goal in the vertical dimension.

Secondly, Wälchli associates deixis and displacement, as becomes manifest in the use of the verbs 'come' and 'go' (cf. Table 1). I propose to disregard deixis as well, since the deictic center taken depends on the deictic stance taken in a particular narrative. For example, it is perfectly possible to have a path such as "F come into G". With these two modifications, the list of cardinal paths can be set up as in Table 1.

Table 1. Cardinal kinds of displacement

\begin{tabular}{lll}
\hline & Wälchli & modified $(R B)$ \\
\hline AD & F go to $\mathrm{G}$ & F displace to $\mathrm{G}$ \\
$\mathrm{IN}$ & F go into $\mathrm{G}$ & F displace into $\mathrm{G}$ \\
SUPER & F go onto $\mathrm{G}$ & F displace up \\
$\mathrm{AB}$ & F come from $\mathrm{G}$ & F displace away from $\mathrm{G}$ \\
$\mathrm{EX}$ & F come out of $\mathrm{G}$ & F displace out of $\mathrm{G}$ \\
$\mathrm{DE}$ & F come down from $\mathrm{G}$ & F displace down \\
\hline
\end{tabular}

Wälchli's idea, together with the core notions from the theoretical and empirical work by Talmy and Slobin, provide the framework within which the dialectological data in the remainder of this contribution will be analyzed. After a short account of the data used here, we will first discuss the lexical patterns found in the verb slot (Wälchli's verbal coding of displacement), then those in the adverbal and the adnominal slot.

\section{Data}

The data have been collected using two well-tested tools. The Frog Story (Mayer 1969) was used in order to elicit reference to motion events. Mayer's picture book consists of 24 panels which show the trajectory of a little boy and his dog searching for their pet frog. The story is well suited for eliciting all kinds of motion in space, since both the boy and the dog run across the forest, fall into a ditch, climb trees, etc. The informants (cf. Table 2) are asked to study the picture book briefly, in order to get acquainted with the plot of the story. Subsequently, they are asked to retell the story, backed up by the picture book. This retelling is recorded and later transcribed and coded for the phenomena discussed here. Note that Talmy's framework does not only apply to motion events. Expressions referring to static spatial relations underlie very similar constraints, and they are thus included where it is appropriate. Static spatial expressions are elicited by using another picture book which has been developed by the Max Planck Institute for Psycholinguistics in Nijmegen (cf. Bowerman 1996). This consists of 71 drawings, each of which has an object (the figure) marked by an arrow. The informants are asked to describe where this figure is located with respect to its physical environment (ground). This task is relatively monotonous, and it is sometimes hard both for the informant as well as for the dialectologist to go through the whole picture book, particularly with older informants who are often unable to see the point of this kind of task.

Table 2. Number of informants per variety for the two data series

\begin{tabular}{lcc}
\hline Variety & Frog Story & Static Relations \\
\hline Standard High German (SHG) & 10 & 5 \\
Muotathal Dialect (MU) & 8 & 6 \\
French (FR) & 10 & 5 \\
\hline
\end{tabular}

The speakers of Standard High German in the sample are all Germans, from different areas of the country. Some of them have been living in Switzerland for some time. Since in Germany and especially in Switzerland the dialect-standard situation must be taken into account, all SHG informants have been chosen on the basis of two criteria: first, they must not have a German dialect as their first language (only a very slight accent was allowed), and second - for those living in Switzerland - they must not speak a SHG which is markedly mixed with Swiss German features.

The Swiss German dialects are represented here by the Muotathal (MU) dialect. The Muotathal is located in the central part of Switzerland, in the canton of Schwyz. The valley is not situated particularly high up in the mountains (altitude: $610 \mathrm{~m}$. above sea level), nor is it particularly inaccessible, but nevertheless it is a place with a high degree of linguistic and cultural idiosyncrasy. The population is characterized by relatively dense, close-knit and multiplex social networks, which can be easily inferred from the small set of last names borne by a large 
portion of the native population. The natives are very proud of their area, and they show great loyalty to their valley. The Muotathal dialect has been chosen here because of its relatively traditional language-ecology conditions. Since I am interested in factors such as the conceptional orality vs. literacy of a variety (cf. section 6), this very traditional area of German-speaking Switzerland with relatively low levels of migration, higher education, and valley-external ties is most likely to offer a contrast to the Standard language.

Some remarks on the Swiss German language situation are necessary to understand the categories in Table 2 (see also Haas 2000: 57-138 and Rash 1998 for a general characterization of the SG situation). The most important point here is that the Alemannic dialects spoken in Switzerland are the first language of virtually all natives, and that there is no 'standard' Swiss German dialect. With rare exceptions (basically internal migrants who mix SG dialects), every Swiss German speaker speaks some clearly regionally marked variety. Although a certain leveling of the small-scale dialect features can be observed, there is no tendency towards a Swiss German koiné, as the study by Christen (1998) has shown clearly (assertions to the contrary, namely in German sociolinguistic publications [cf. e.g. Dittmar 1997: 80], are based on traditional misunderstandings and projections of the German situation onto the Swiss context). Although the term diglossia certainly has some problematic aspects, the Swiss German situation still resembles very much the picture given in Ferguson (1959). The Swiss case of diglossia is characterized by functional differentiation - SG is used orally and SHG in all formal written contexts. The main domains of oral use of SHG in German-speaking Switzerland are as the language of instruction (although, once again, not categorically) and the language of some programs in the electronic media (news, movies). This medially constrained diglossia is an important aspect in the attempt to explain the variation patterns shown in sections 4 and 5 below.

Since one of the points of the present contribution is to show that S-languages (such as SG) do not always behave the way typologists would expect them to, French has been added to the data sample in order to compare the two S-language varieties of German with a V-language. The speakers of French in the sample are all native speakers of French. They are all natives of the French-speaking part of Switzerland, although some of them live or have lived abroad (in France, in the US). Since most of the features which differentiate Swiss French from Parisian French are lexical and prosodic, they do not affect our data. Pleonastic constructions such as monter en-haut 'climb up' instead of the simple use of the path verb monter, which can be observed in colloquial French in Switzerland and elsewhere, do not occur at all in our data.

Since the data under investigation here are part of an ongoing project on spatial language in German and its neighboring Romance varieties, the number of informants is not the same for all varieties. However, given the tradition both in typology and dialectology of taking one single text or informant to represent a dialect or language, the sample here is nevertheless more 'representative' than what has been the rule so far. One of the aims of the aforementioned larger-scale project on spatial language will be to investigate social stratification of variation phenomena such as those discussed here. For the sake of brevity, however, sociological variables such as gender, age, and education have to be disregarded in the present analysis.

\section{The verb slot: Motion and posture verbs}

As discussed in section 2, one of the major typological issues in the realm of motion verbs is the difference in the use of path verbs and manner verbs. In this section, the verb slot in the Frog Story retellings will be analyzed. The three varieties/languages used in this contribution will be juxtaposed and compared, using the categories established both by Talmy and by Wälchli. In the second part of the section, the verb slot of the static data will be discussed and compared in a similar way.

\subsection{Motion verbs}

The Frog Story data have been analyzed with respect to the way the verb slot of a motion event is filled. Whenever a figure changes its location in the retelling, a more or less complex construction referring to movement (=activating process), path (=association function) and - optionally - ground (either the source of the trajectory, a milestone on the trajectory, or the goal) and maybe manner of motion is used. Figure 3 shows the proportion of path verbs relative to the total number of motion verbs, grouped by the three languages/varieties. The non-shaded parts of the columns represent the percentage of verbs which do not code any path information. 


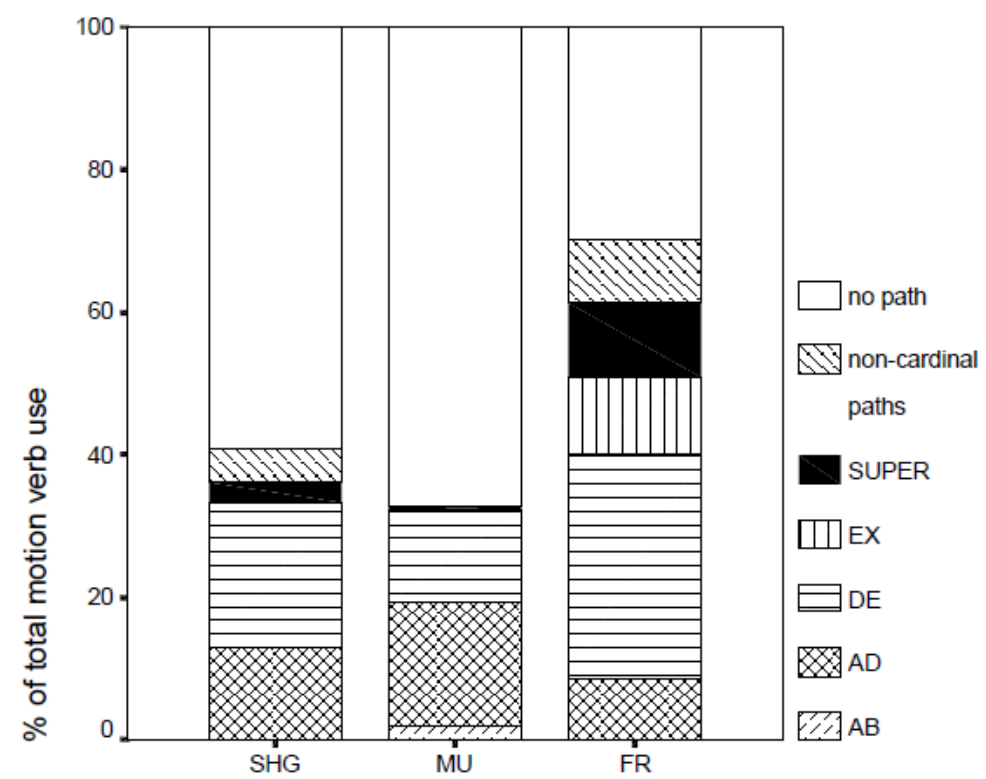

Figure 3. Cardinal kinds of displacement in the three linguistic varieties (see Table 1)

As typologists expect and predict, speakers of French, on the whole, use more path verbs than speakers of German. The difference is considerable both when comparing French with the Muotathal data as well as with SHG. Additionally, the figure not only shows global differences of path verb usage, but also displays the exact locus of this difference: whereas French has a path verb expressing EX paths (sortir), German does not. French also has a path verb for IN paths (entrer), however, due to the particular features of the plot, entrer does not show up at all in the data. Another important difference is the very frequent use in French of DE verbs (mainly the verb tomber), whereas German fallen and Muotathal dialect kchiie are used less frequently. The French data also display more usage of SUPER verbs (monter); interestingly, this category of path verbs is almost negligible in the Muotathal data.

If we compare the path verbs of the Muotathal dialect and SHG, we discover a very frequent use of AD verbs in the former, which is basically due to the high frequency of the verb cho (SHG kommen [='come']), as in examples (6) and (7).

(6) dä chömmeds änefür wider a öppis aane

then come-they yonder again at something towards

'then again they come to something'

(7) und obe isch ejä de Uhu cho and above is yes the owl come 'and above the owl appeared'

It is at least questionable whether the verb cho in all instances represents a path verb. Whereas in some examples it clearly has the semantics of a path leading towards a ground object (as in example 6), in others (example 7) the verb simply means 'to appear' or 'to move'. This non-path usage of cho kommen is not impossible in SHG, but it is not nearly as frequent as in the Muotathal dialect. Since the line between path and non-path usage of cho is not easily drawn, all instances of cho have nevertheless been tagged as path verbs. It thus could be argued that for the Muotathal dialect the proportion of the AD path verbs in Figure 3 could shrink to a value close to the SHG value. This would even increase the difference between SHG and the MU in terms of overall path verb usage.

Whereas Figure 3 is an account of the motion verb usage in the data, Figure 4 renders the degree of co-event integration in the verb slot. As we have seen in section 2 above, the 'standard' co-event in the realm of motion verbs is the manner of motion, i.e. additional information about the modality of displacement. Examples (8) to (10) contain instances of manner verbs from all three languages/varieties.

(8) schlich er sich leise heimlich aus seinem Terrarium

sneaked he himself silently secretly out-of his+DAT terrarium

'he sneaked silently out of his terrarium' 
(9) dass de gugger da so umeschwirrt that the cuckoo there [] around-whirrs 'that the cuckoo whirrs around there'

(10) il saute sur la ruche

'he jumps onto the beehive'

Again, just as in the case of the motion verbs, there is no doubt that all varieties do have manner-of-motion verbs. The question here is how frequent they use them. Figure 4 displays the frequencies of manner verb usage, again grouped by the three varieties.

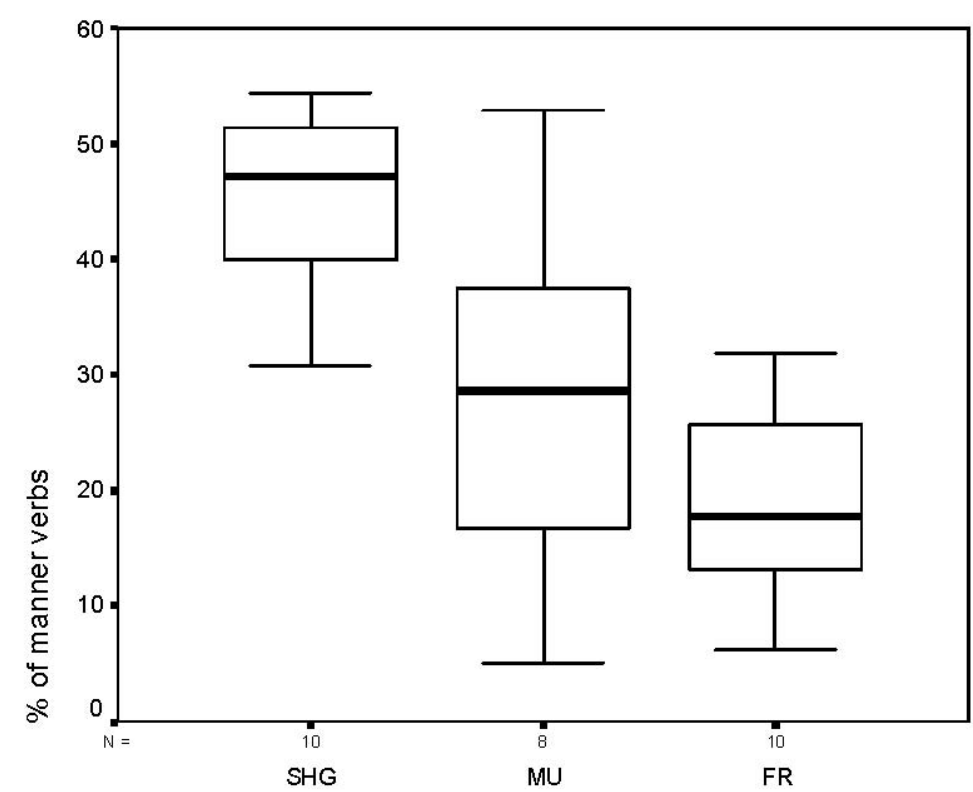

Figure 4. Proportion of manner-of-motion verb usage in SHG, MU, and FR

As Figure 4 shows clearly, the usage of manner verbs varies considerably. Boxes represent the middle $50 \%$ of the values, the median (dark line) as the best representative of the distribution, and the vertical lines indicate the scattering of the whole sample. The box plot was chosen as the best chart type since it shows medians and distributions at the same time. Every speaker of SHG, MU, and FR is treated as an individual case with his/her score for manner verb use. The median, as the best representative of a distribution of ordinal-scale values, shows clearly that FR has the lowest values for manner verb usage, confirming the typologists' expectation. For SHG, on the other hand, the plot reflects a considerably higher use of manner verbs, with very little overlap with the FR data. The speaker of SHG with the lowest use of manner verbs uses about as many manner verb tokens as the speaker of FR with the highest scores. MU, in the middle of the chart, shows a peculiar distribution. First, the scattering is very wide, with the highest values close to the highest value of SHG and the lowest value even lower than the lowest FR values. Second, the median is much lower than that of SHG, and the MU sample as a whole is statistically significantly different from the SHG sample (independent sample t-test, $\mathrm{p}<0.01$ ). Using the same statistical procedure to compare $\mathrm{MU}$ and $\mathrm{FR}$, the difference turns out to be not significant ( $\mathrm{p}=0.121$ ). As a preliminary result we can state that, regardless of the undoubted S-language status of MU, its usage of manner verbs is not significantly different from FR (a V-language). SHG, on the other hand, is significantly different from MU and FR. 
Another striking difference between MU and both SHG and FR is the very high proportion of non-motion verbs in the MU data (19\% vs. SHG 0\% and FR 0\%). Frequently, the verbs heading a motion VP are auxiliaries (i.e. the motion verb participle is not specified, cf. [11]), modals (12) or even Ø (13).

(11) der hund isch em hirsch nache the dog is ART+DAT deer after 'the dog follows the deer'

(12) der bueb wott ufe baum ufe the boy wants up+ART tree up 'the boy wants [to go] up into the tree'

(13) de frosch ussem glas the frog out-of-the+DAT jar 'the frog [went] out of the jar'

The use of the AUX sii (SHG sein [=‘be’]) as a motion verb is by no means a SG speciality; it can be found in southern German dialects as well (Stadelmann 1978: 111). According to the Duden Grammar (cf. Eisenberg et al. 1998: 92), sentences like (12) are possible in SHG, too, and it is commonly understood as an elliptical construction which omits the participle. However, in our SHG data, this type of construction does not occur at all.

\subsection{Posture verbs}

For the linguistic description of static configurations, the same framework as the one used for the motion verbs can be applied. However, at least in the languages used in this contribution, there is no direct parallel to path verbs in the realm of static spatial language. Since neither German nor French has verbs expressing core schemata such as 'being on top of $X$ ' or 'being near X', there is no need for an analysis of 'core schema verbs' in this case. Consequently, even the V-language FR provides a verb slot which is always available for the expression of co-event information. We thus expect smaller differences here between German and French than in the case of the motion verbs. Although Talmy explicitly includes static relations in his event-structure framework (cf. section 2 above; Talmy 2000b: 218 and 221), he does not present any further analysis of static expressions, and - as far as I know - he does not explain why the 'core-schema' verbs in many languages only exist for lexicalizations of pathand not of place-core schemata.

However, there is no doubt that in all three varieties, manner co-events can be expressed in the finite verb, as examples (14) to (16) illustrate.

(14) der Schlauch liegt auf dem Baumstumpf

the hose lies on the+DAT stump

(15) dr schluuch hanged über de baumwürz

the hose hangs over the stump

(16) la cordelette gît sur le tronc

the rope lies on the stump

Manner verbs here are predominantly posture verbs (e.g. sit, stand, lie, hang; cf. Newman 2002), i.e. verbs which encode configurational information about the dimensions and the vertical or horizontal orientation of the figure. In addition to posture verbs, some informants use verbs such as hide, rest, etc. As an alternative to the constructions in (14)-(16), all three languages/varieties can, to a certain extent, use complex predicates consisting of an AUX and a participle (=co-event participle), as illustrated in examples (17) to (19). The participle in these latter constructions refers to the final state of a motion event, mainly a transitive motion event (e.g. an actor hangs the figure somewhere, and now it is hung).

(17) de chittel isch amene haggä ufghänkt

the jacket is at-a+DAT peg up-hung

'the jacket is hung up on a peg' 
(18) das Tuch ist um den Kopf geschlungen the cloth is around the+ACC head wrapped 'the cloth is wrapped around the head'

(19) le veston est suspendu à un crochet the jacket is hung on a peg

Since the latter constructions, too, convey information about the alignment and position of the figure (i.e. 'manner of position'), it is useful to include these constructions in the global count. Figure 5 shows the proportion of co-event verbs, again in the box plot style already used and explained in Figure 4.

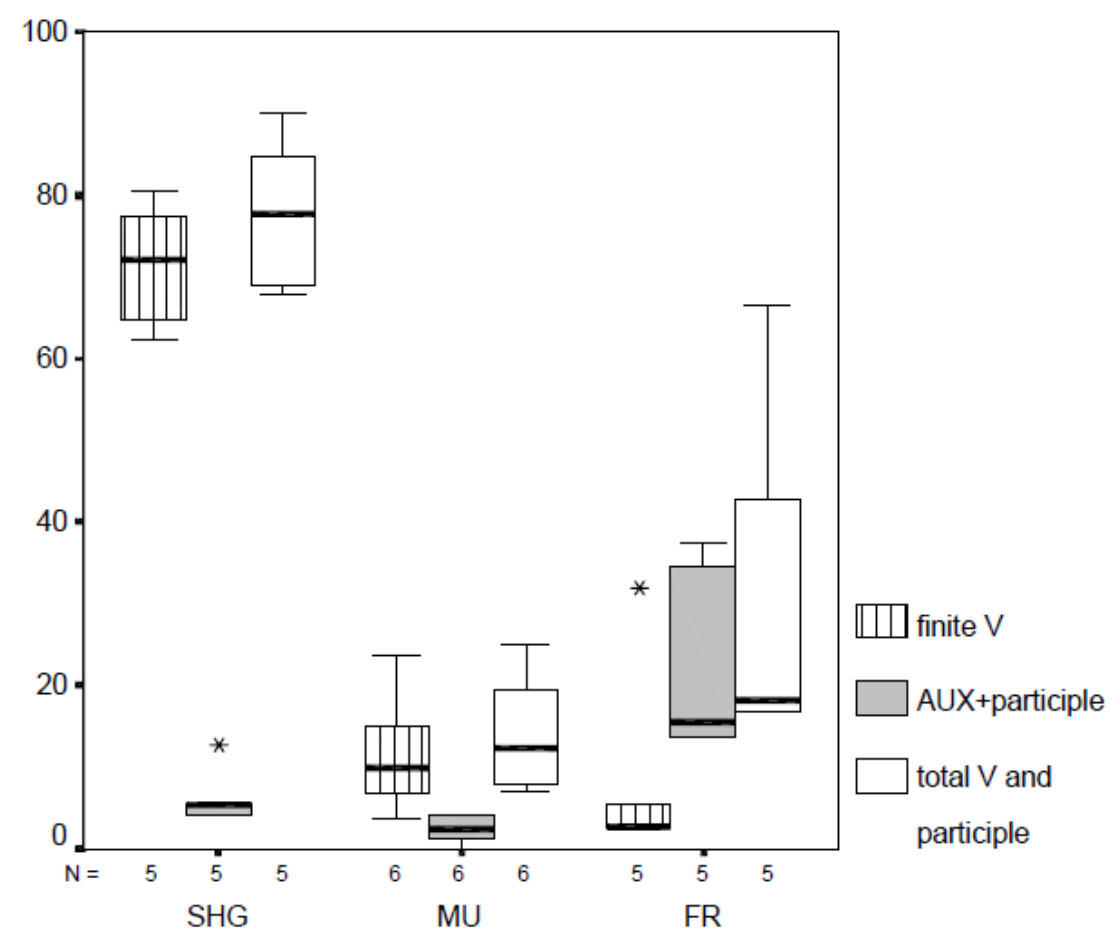

Figure 5. Posture verb usage in the static data. The left-hand boxes represent coevent integration in the finite verb, the middle boxes co-event participles, and the right-hand boxes the total.

The differences here are even more striking than in the motion verb count. SHG shows extremely high values almost all informants use posture verbs in the great majority of the responses. The scattering for SHG is narrow, with the lowest values at around $60 \%$ of the answers and the highest at about $80 \%$. There are only very few examples of AUX+Participle predicates in either SHG or MU. However, in contrast to SHG, MU is extremely poor in the usage of finite manner verbs. It turns out that all MU informants overwhelmingly used the verb sii 'be'. The MU scores are so low that even the speakers of French, who were expected to be more similar to the speakers of German here than in the motion verb count, turn out to use more manner verbs than the speakers of MU. As the figure shows clearly, French strongly prefers the AUX+Participle construction discussed above (examples 17-19).

In this section, the verb slot and its filling with core-schema and co-event content have been analyzed. In certain respects, the typological expectations have been confirmed: as far as the expression of path is concerned, French and both varieties of German behave the way typologists predict. However, in other respects, namely the expression of co-events, the picture is more complex, and in particular the MU dialect looks more like a non-manner salient V-language. SHG, on the other hand, seems to fit the typologists' expectations for both criteria examined in this section. An appreciation and discussion of these results will be attempted in section 6 , after an in-depth analysis of the verb-sister position in the next section 5.

\section{The verb-sister slot: Path and place arguments}

As outlined in section 2, the locus of the association function is either the verb slot or a constituent of the VP which 
is adjacent to the verb (cf. Figure 2 and examples 20-24). In the latter case, it can either be instantiated by an adverb alone (i.e. a satellite in Talmy's terminology, cf. Talmy 2000b: 222) or by a PP. As outlined in section 2, German is generally seen as an S-language, i.e. a language which canonically maps the core schema onto a particle in the verb-sister position. However, Talmy's term S-language seems to be slightly biased by a structural property of English. Consider examples (20) to (24).

(20) le garçon sort

the boy exits

(21) the boy comes out of the house

(22) the boy comes out

(23) der Junge kommt heraus

the boy comes TOWARDS-out

(24) der Junge kommt aus dem Haus

the boy comes out the+DAT house

There is no doubt that in the French example (20) the path is expressed in the verb root. In the English examples, the path is expressed in the particle out, which is a typical satellite in Talmy's terminology. Example (21) not only expresses the path but also a ground element in the PP of the house. In a way, the P of again expresses a very schematic path, referring to displacement away from a source. In the German examples, finally, we see that the path satellite is dropped once the ground element is introduced in a PP. Although there is no doubt that German typically does not map the path onto the verb root, it does not always have path satellites. As soon as a ground object appears, the association function is in the head $\mathrm{P}$ of the constituent, and no satellite is involved. It thus makes perfect sense to distinguish two types of non-verbal coding of the core schema, adverbal (=satellite) and adnominal (=PP) marking (as proposed by Wälchli 2001: 301). Both are in a sister position to the head of the VP, and both are, of course, arguments rather than adjuncts.

Finally, the German (both SHG and MU) data contain another construction, as shown in examples (25) and (26). This type of construction has attracted some attention from both dialectologists (Staub 1881-, vol. 2: 1319; Stadelmann 1978: 108) and syntacticians (Olsen 1996: 305; Eisenberg et al. 1998: 399; McIntyre 2001: 63; Pittner 1999: 55).

(25) der Junge kommt aus dem Haus heraus

the boy comes out the+DAT house TOWARDS-out

a. ...dass der Junge [aus dem Haus] [herauskommt]

b. ...dass der Junge [aus dem Haus heraus] [kommt]

(26) der Hund sitzt in der Hütte drin

the dog sits in the kennel in[side]

The exact syntactic status of the construction in (25) and (26) is not clear. As Olsen (1996: 306) points out, the adverb can be seen either as taking part in a verb complex as in (25a), or as part of a complex PP as in (25b). Example (25a) represents a construction very similar to the English satellite in example (21). Other syntacticians clearly opt for the second variant, and in this case the adverb is considered the head of the argument constituent and the PP its modifier (Pittner 1999: 54). However, although there are different syntactic accounts of this construction type, it is generally admitted that the structural variants do not imply major shifts in the semantics of the construction (Pittner 1999: 55). Since we do not have the space for an in-depth syntactic analysis here, it shall suffice to distinguish between the simple path and place arguments, as in (23) and (24) on the one hand, and complex path and place arguments as in examples (25) and (26) on the other.

In the remainder of this section, the details and frequencies of the simple and complex path and place arguments will be outlined. Since there is not a single instance of a complex construction in the French data, the comparison can concentrate on the varieties of German.

5.1. Path arguments

The example of a complex path argument given above in example (25) represents a case in which the adverb and 
the P prompt the same association function. These constructions thus are often labeled pleonastic or redundant (e.g. Olsen 1996). The question arises whether (24) and (25) in fact really do mean exactly the same thing, or whether a semantic differentiation is possible. This question will be discussed below. Here, I propose to accept the redundancy claim as a working hypothesis. However, not all adverbs and Ps - lexically - code the same spatial schemata, as (27) demonstrates. In addition, the use of a composite adverb, as in (28) allows us to add the coding of movement towards or away from a transposed deictic center.

(27) er hed en inne Teich appe grüert

he has him in-a pond down thrown

'he threw him down into a pond'

(28) schlich er sich aus seinem Terrarium heraus

crept he himself out his+DAT terrarium TOWARDS-out

'he crept out of his terrarium'

For a frequency count of the complex path arguments, it is thus useful to distinguish the pleonastic constructions and the semantically complemen-tary constructions as in (27). This is shown in Figure 6.

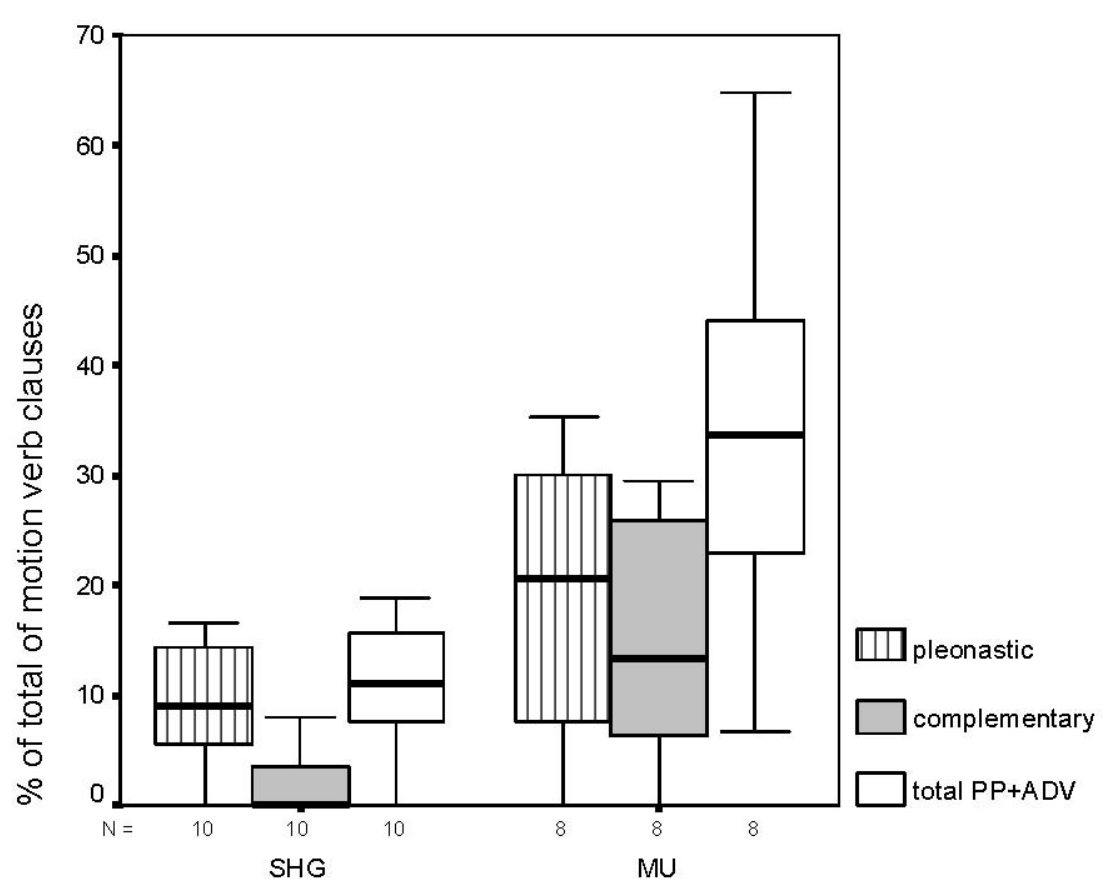

Figure 6. Complex vs. simple path arguments in the SHG and MU Frog Story data

What strikes us immediately in Figure 6 is the much higher average use of complex path arguments in MU. The total use of the PP+ADV construction is significantly higher in MU (independent sample t-test, $\mathrm{p}<0.01$ ). Whereas the pleonastic constructions are not significantly more frequent in MU compared to SHG ( $\mathrm{p}=0.072$ ), the complementary constructions are $(\mathrm{p}<0.05)$. Again, in MU the scattering is relatively wide, with some informants hardly ever using complex arguments and others using them in almost $70 \%$ of all motion event constructions. In SHG, some redundant constructions occur, but the complementary constructions are extremely rare.

In the MU sample, the most common combination of redundant Ps and adverbs are the doubling up of the EX and IN paths (8 out of $29=28 \%$ for both, cf. examples 29 and 30). The largest group ( 8 out of $24=33 \%$, cf. examples 31 and 32) within the set of complementary constructions are instances of a DE path, i.e. downward motion in combination with either an EX or an $\mathrm{AB}$ path: 
(29) de hund hed nümme chönne usem Glas uuse the dog has no-more can out-the+DAT jar out 'the dog could not [come] out of the jar anymore'

(30) er mües au no is glaas ine

he must+CONJ. also yet into-the jar inside

'he had [to go] into the jar, too'

(31) ischt er usem baum abbe ghiit

is he out-the+DAT tree down fallen

'he fell down out of the tree'

(32) isch er wieder vom baum abbe ghiit

is he again from-the+DAT tree down fallen

'he fell once again down from the tree'

Whereas we assume that the redundant constructions do not imply a major difference in cognitive construal of the motion event, it is important to note that constructions such as the one in (31) in particular represent a different, more complex construal of the scene: the figure is not only moving on a downward path, it is also 'exiting' the tree space, construed as a schematic container. The MU data are thus not only characterized by more redundancy in the syntactic slot of the path argument, but also, to a certain extent, by a more elaborate mental construal of the motion event.

\subsection{Place arguments}

In this section, the static data are analyzed, using the same categories as in section 5.1. Again, pleonastic and complementary constructions can be found in the data (cf. examples 33 to 36).

(33) dr schluuch isch um d baumwürz ume

the hose is around the stump around

(34) de hund isch im hüüsli inne

the dog is inside+DAT-the house-DIM inside

(35) da hed er öppis am chopf umebbunde

there has he something at-the+DAT head around-tied

'there is something tied around his head'

(36) d tanne isch am rain obe

the fir is at-the+DAT flank (of the mountain) above

In the MU data, there are 50 such examples and 3 in SHG. The spatial relationship of encirclement (cf. example 33) accounts for 17 (34\%) of the redundant place arguments in MU, and 2 (66\%) in SHG. The containment relationship (cf. example 34) is doubled up in 15 (30\%) of the MU data and in 1 (33\%) of the SHG sentences.

Figure 7 displays the distribution of pleonastic and complementary place adverbials. 


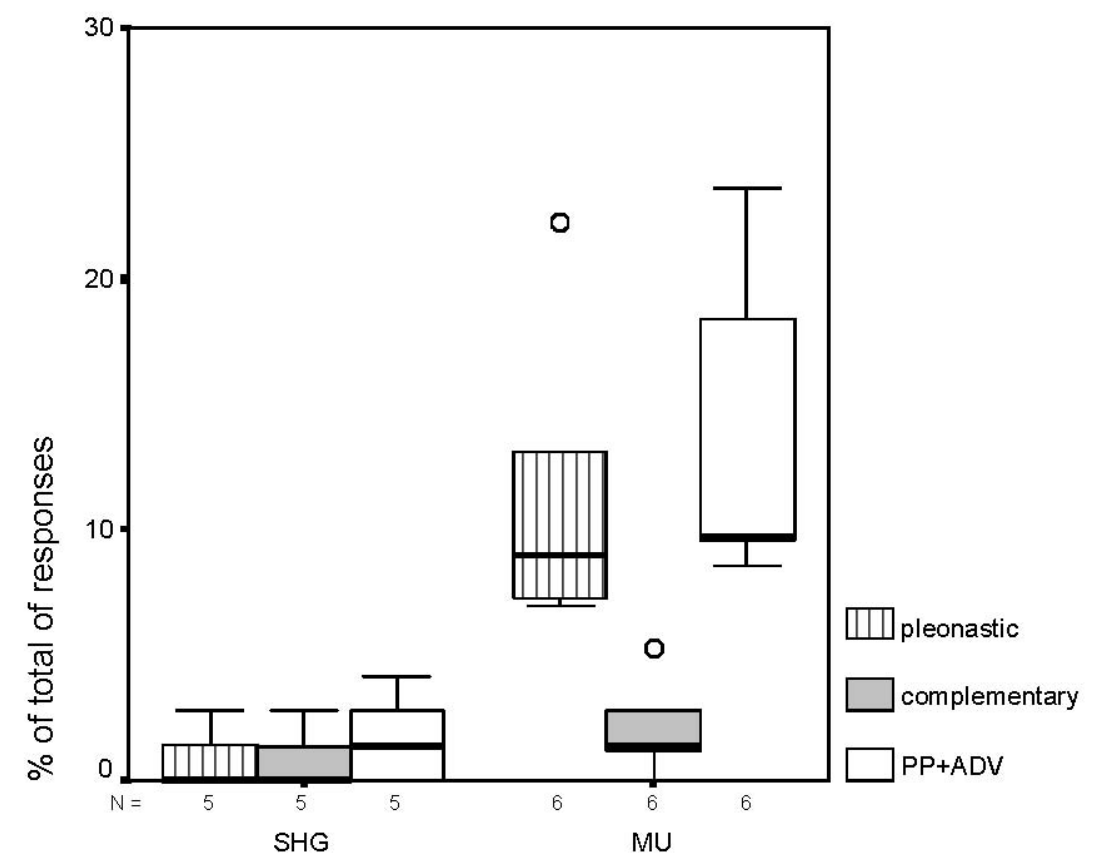

Figure 7. Pleonastic and complementary place arguments in the MU dialect and in SHG

Again, the figure shows considerable differences between the MU dialect and SHG. Although complex place arguments are structurally possible, they are statistically almost negligible in SHG. The MU informants' data are characterized by an average of about $10 \%$ redundant constructions, although the outlier (ME4) shows, that one informant has a score of about $20 \%$. As the chart suggests, the differences between MU and SHG are statistically very significant for the pleonastic constructions and for the total of the PP+ADV constructions (independent sample t-test, $\mathrm{p}<0.01)$.

The analysis of the place arguments supports the main evidence from the path argument section above, i.e. MU tends to have more complex constructions than SHG. At the same time, the static data do not evidence a great deal of complementary constructions.

As mentioned before, the question arises of whether the semantically redundant complex arguments are really equivalent to their corresponding simple PP-constructions. Examples such as (34) above could be evidence of a similar distinction as between English in vs. inside, i.e. partial vs. complete containment of the figure in the ground. However, for several reasons, the data analyzed in this sample do not support this type of differentiation. First, the dog in the picture which stimulates responses such as the one in (34) is not completely inside the kennel. Pleonastic constructions are even used for a picture stimulus showing a man smoking a cigarette, which for the greatest part is undoubtedly located outside the mouth:

(37) d zigerette wo imenä muul innen isch the cigarette that in-a mouth inside is

None of our informant groups even approximately uses the complex argument constructions categorically for a particular picture stimulus. Since both simple PPs and complex PP+ADV constructions occur for the same pictures and in the same varieties, the data analyzed here do not support any systematic semantic differentiation other than the 'redundancy hypothesis'. However, other means of data elicitation and/or meta-semantic judgments by informants might shed more light on this issue.

To conclude this section concerning place and path arguments, it seems clear that both static and dynamic expressions show similar patterns of variation within the German varieties: the MU dialect is characterized by a significantly higher degree of complex local arguments, and at least in the dynamic data this corresponds partially to a higher resolution of the spatial scene, a difference in mental construal. This more elaborate expression of the association function is undoubtedly a salient form of “distributed spatial semantics” (Sinha and Kuteva 1995: 187). Sinha and Kuteva in fact propose an additional typological axis, representing the overtness or covertness of the expression of the association function (1995: 191). On this axis, MU clearly is an example of a (variety of a) language with a high degree of overtly expressed spatial relational semantics. 


\section{Conclusions}

In the two preceding sections, the lexical and syntactic realizations of the verb slot and of the path and place arguments have been compared. The main findings can be summed up as follows:

1. According to typologists' claims, French versions of the Frog Story contain more path verbs than their German counterparts.

2. However, there is no categorical difference between the S-language German and the V-language French: the main difference between the two languages, in the realm of path verbs, is the lack of EX and IN verbs in German. A refined typology, such as the one proposed by Wälchli, allows for a much more precise typological assessment than the simple dichotomy used by Talmy, Slobin and others.

3. Again, according to what typologists have observed, SHG versions of the Frog Story show a higher usage frequency of manner verbs (both dynamic and static). Remarkably, there are significant differences only between Standard High German and Standard French. The MU dialect is characterized by a rather infrequent use of co-event verbs. MU thus - statistically - is closer to French than to Standard High German for the co-event feature. This result clearly does not match the typologists' predictions.

4. Whereas the verb slot can be observed to be lexically less elaborate in MU compared to SHG, the path and place argument slot is significantly more complex in MU both in syntactic and in lexical terms. In the MU dialect, a simple PP very often does not seem to be sufficient for the expression of the figure's location and path.

5. For dynamic expressions, this complex path predicate in MU often involves two aspects of a complex path, rather than one path as in SHG.

\subsection{What can typologists learn from dialectologists?}

Typologists - for methodological reasons - often have to simplify their subject matter in two ways. First, since they often attempt to deal with a great number of the world's languages, they have to focus on homogenized categories such as 'German', 'Spanish', 'French', etc. On the other hand, it is the dialectologists' job to look at regional and - since good dialectology includes social dialectology - social variation within a particular 'language'. I am convinced that the data presented in this contribution show clearly that once we zoom in on those idealized categories, we discover patterns which go against the larger picture drawn by typologists.

Second, typologists often have to rely on rather unnatural linguistic data. Take the study by Wälchli (2001) discussed in section 2 above: for the sake of comparability, the 40 languages in Wälchli's sample are represented by a single text of a rather specific kind, a bible translation. This text type not only tends to exclude dialectological and sociolinguistic variation, but, canonically, it also represents a particular form of the standard language, namely the extreme of conceptional literacy on a continuum between literacy and orality (cf. Koch and Oesterreicher 1985: 18 and the discussion below). Whereas typology often has to rely on such relatively 'unnaturalistic' data, dialectologists, by definition, attempt a much more fine-grained analysis of - predominantly oral - use of language. Given this difference in scope of the linguistic subject matter, the dialectological analysis carried out in sections 4 and 5 can shed some new light on the typological classification proposed by Talmy (2000b: 117), as has been stated in conclusion (3): Not every satellite-framed language is a manner-salient language. If we remember the frequent use of complex path and place predicates in the MU dialect, we can conclude that this dialect uses satellites together with PPs, just like (Standard) English and unlike SHG (cf. the discussion in section 5). MU thus is clearly an S-language, but an S-language which does not express significantly more manner than the V-language French.

In order to illustrate what kind of complementary perspective dialectologists can offer to typologists, and in the present contribution particularly to Talmy's typological work, let us turn briefly to Talmy's discussion of Yiddish in contact with Slavic. Here, Talmy focuses on constructions which strongly resemble the MU constructions analyzed in this contribution, as illustrated in example (38). 
(38) Bald vi er iz aroyf[getrotn] oyf dem tretar, iz er arayn[gegangen/gekumen] in der kretshme.

Square brackets indicate that the participle can be omitted. (38) should look very familiar, since it involves the ellipsis of the nonfinite motion verb as discussed in section 4.1. (cf. example 11 and the pleonastic expression of path discussed in section 5.1.). However, Talmy attributes the latter phenomenon to contact with Slavic:

Yiddish retains from Germanic the option of omitting a nonfinite motion verb from a sentence that contains a path-specifying satellite or prepositional phrase. Omitting the verb in this way is not a Slavic pattern. But Yiddish intersects this pattern with the borrowed Slavic pattern of coupling a reduplicative satellite with a preposition [...]. Thus, while German can omit a motion verb in the presence of a path prepositional phrase alone, Yiddish must also include a path satellite there, as in (18 [=(38), RB]). (Talmy 2000b: 309)

Talmy seems to be claiming that the construction with a satellite and a PP is categorical in Yiddish. Let us assume this is the case, although Talmy does not provide any statistical evidence for his claim, nor does he indicate the corpus on which his analysis is based. In section 5.1., I have shown that this pleonastic pattern is very frequent at least in one variety of German. Dialectologists from geographically non-contiguous areas have observed the same syntactic patterns in other German dialects (e.g. Harnisch 1982: 119). Although the issue of categoriality implied in Talmy's quote remains an open problem, there is no need to assume a direct causal connection between the complex path arguments, on the one hand, and Slavic-Germanic contact, on the other: If the pattern appears to be a genuinely German one - admittedly not one of SHG - this is the much more likely reason for its existence in Yiddish. The Slavic adstratum might have a supporting effect for this type of construction, and it may well be that the phenomenon in Yiddish owes its possible categoriality to such an adstratum effect. But clearly a closer look at the dialectal variation within German allows us to avoid drawing hasty conclusions about language contact phenomena.

Since dialectologists prototypically deal with language forms which are either the locus or at least remnants of oral culture, the issue of orality vs. literacy has to be addressed here. Koch and Oesterreicher (1985) claim that language use - both written and spoken - can be located on a cline between a conceptionally oral and a conceptionally written pole. For our present purposes, this means that even oral language use can show features of conceptionally written language. And, on the other hand, written varieties can show features of conceptional orality. Oral language is what Koch and Oesterreicher also labelled language of closeness ("Sprache der Nähe"; 1985: 21; Oesterreicher 2001: 1565-1570). The conceptionally oral form of language has a lot to do with Givón’s pragmatic mode (1979: 229), as opposed to the syntactic mode, which corresponds to the language of distance ("Sprache der Distanz"). Koch and Oesterreicher offer a large number of features which characterize the language of closeness (1985: 27; 1994-1996: 591; 2001: 1568). Some examples are anacoluthic and elliptic constructions, congruence violations, holophrastic utterances, paratactic structures, low type-token ratios in the lexicon, hyperbolic expressions, and many pragmatic phenomena such as turn-taking signals, self-corrections, etc.

Two features of the language of closeness are of particular interest here: redundancy and lexical variation/elaboration. As shown in section 3, the diglossia in German-speaking Switzerland imposes predominantly functional constraints (written vs. spoken language) on the use of the two varieties of German involved. In its (completely non-standardized) written form, Swiss German is almost exclusively used in contexts pertaining to the language of closeness, i.e. private letters and postcards, internet chats, etc. It is thus justified to assume that SG, on the whole, preserves important features of the language of closeness. In most parts of Germany, on the other hand, dialects are dying out or are at least socially stigmatized. Therefore, conceptionally literate SHG dominates most everyday usage contexts. SHG, as Reichmann (2003) has shown clearly, is very much a product of a long transition process from conceptional orality to conceptional literacy. Undoubtedly, the oral use of SHG in contexts where, traditionally, dialects had been spoken introduces features of conceptional orality into the standard language. But the fact that the norm (generally attributed to the Duden Grammatik and Duden Rechtschreibung, handed down to the speakers via schooling) is based on the conceptionally written form of SHG has important influences on the oral use of SHG. If those assumptions are correct, we would expect oral SHG to show fewer features of the language of closeness than the SG dialect. And this is exactly what we find in the data analyzed in the present contribution: MU data show considerably less lexical variation in the verb slot than the SHG data; the manner of motion and the posture of the figure are by default not characterized, unless they require particular attention in the actual discourse. Furthermore, the elliptic use of the auxiliary as a motion verb (cf. section 4.1), which can only be found in the MU data, is another typical feature of conceptionally oral language (Oesterreicher 2001: 1568). SHG, on the other hand, elaborates by default on the different ways of moving and being positioned in space. This corresponds exactly to one of the aforementioned differences between language of distance and language of closeness. 
The path and place predicates, on the other hand, show a different pattern. As has been shown in section 5 , the locus of the core schema of spatial expressions is syntactically more elaborate in MU than in SHG. Whereas SHG seems to focus on the co-event part of the spatial localization event (cf. section 4), MU focuses more on the association function. Again, for a conceptionally oral variety it makes perfect sense to emphasize the core schema of an expression instead of the rather secondary co-event. The redundant cases thus correspond to Koch and Oesterreicher's claim that conceptionally oral language is more redundant than its written counterpart (1994-1996: 591), and its higher frequency in the dialect data fits perfectly well Stein's (1996: 38) principle "No double surface realization” for written standard languages. The cases with complementary prepositions and adverbs could be understood as a more fine-grained resolution of the spatial scene - which could be connected to the common hypothesis that rural and in particular alpine populations' linguistic repertoires are more elaborate in the area of spatial orientation (for the alpine Alemannic Walser colonies, cf. Frei 1970: 351; for a comprehensive treatment of spatial language and linguistic relativity cf. Levinson 1996).

\subsection{What can dialectologists learn from typologists?}

The second fundamental question this volume wants to address has - implicitly - already been answered in this contribution. In my view, one of the most important issues in present-day variationist linguistics is to bring together the enormous amount of knowledge of details from the synchronic and diachronic aspects of varieties all over the world. Dialectologists and sociolinguistis have to progress beyond the stage of hunter-gatherers in which, unfortunately, many of us are still working. Just as in the early days of European dialectology, when dialectologists were busy empirically testing the neogrammarians' theoretical assumptions (Berthele, forthcoming), they should reconnect today with the neighboring linguistic disciplines which are trying to address universal issues of language use and how the latter shape linguistic forms. Functional and usage-based theories from the realm of typology, cognitive linguistics and psycholinguistics offer a great repertoire of theories and concepts which can easily be adapted within a variationist/dialectological framework. The present study is of course but a very modest attempt to achieve a (more) re-united discipline, but I am convinced that, at least in the domain of spatial language, typological frameworks offer at least two great advantages. First, they help systematize the research object in the way Talmy's proposal systematizes the realm of spatial language. Second, they allow us to code and analyze cross-linguistic and cross-dialectal data in a transparent way. Both are prerequisites for connecting dialectological research findings with the latest developments in linguistic theorizing and analysis.

Notes

1. The author is greatly indebted to Jean Hannah for her comments on an earlier version of this paper. Many thanks go to Bernd Kortmann, Lieselotte Anderwald, and Bernhard Wälchli for further helpful remarks, as well as to Michael Ehrler for collecting parts of the Muotathal data, and to Franz Schelbert for introducing me to members of his large Muotathal family.

2. It is important to note that, even though there is influence from SHG on the SG varieties, the distinction between SG dialects and SHG is - in the linguistic awareness of any native speaker of SG - very salient and sharp. Only Germans who gradually learn SG form a (sociolinguistically low-prestige) interlanguage between SG and SHG.

3. These types of constructions are generally considered 'bad French': “Pourquoi répéter et diluer puisque monter a un sens bien clair et qui est présent à l'esprit.” (Cohen 1963: 55; cf. Dupré 1972: 1644).

4. The mean difference between the amount of path verb usage by the SHG/MU informants on the one hand and the FR informants on the other hand is statistically significant (independent sample t-Test: SHG-FR $\mathrm{p}<0.01$; MU-FR $\mathrm{p}<0.01$ ).

5. Note that, as opposed to Romance languages, there is not obligatorily a deictic meaning in German kommen/cho. In example (6), cho can also be understood as a mere path verb focusing on the goal of the path (cf. Di Meola 1994: 60-85).

6. Note that there is a structural property in the Swiss German (as well as other Alemannic) dialects which facilitates the elliptic constructions: the loss of the synthetic past forms ("Präteritumschwund"), i.e., in these dialects, the past tense can only be grammatically expressed by the auxiliary plus a past participle.

7. There is little doubt that, as the number of investigated languages and varieties grows, Talmy's basic typology will undergo many further revisions (cf. e.g. the category of "equipollently framed languages", Slobin [forthcoming]). As Bernhard Wälchli (personal communication) points out, displacement, from a typological point of view, remains still largely unexplored.

8. There is no doubt that, in certain particularly salient domains, the language of closeness can display extremely rich lexical repertoires (cf. Koch and Oesterreicher 1985: 27). This has been an issue in dialectology for quite a while, including the domain of spatial language (cf. Frei 1970: 351). 


\section{References}

Berman, Ruth A. and Dan I. Slobin

1994 Relating Events in Narrative: A Crosslinguistic Developmental Study. Hillsdale, NJ: Lawrence Erlbaum Associates.

Berthele, Raphael

forthc. Dialektsoziologie. Soziolinguistische Aspekte in der Dialektologie. In: Ulrich Ammon, Norbert Dittmar, Klaus J. Mattheier and Peter Trudgill (eds.), Sociolinguistics. Soziolinguistik. Ein internationales Handbuch. 2. Auflage. Berlin/New York: Mouton de Gruyter.

Bowerman, Melissa

1996 Learning how to structure space for language: a crosslinguistic perspective. In: Paul Bloom, Mary A. Peterson, Lynn Nadel and Merrill F. Garrett (eds.), Language and Space, 385-436. Cambridge, MA/London: The MIT Press.

Christen, Helen

1998 Dialekt im Alltag. Eine empirische Untersuchung zur lokalen Komponente heutiger schweizerdeutscher Varietäten.

Cohen, Marcel Tübingen: Niemeyer.

1963 Nouveaux regards sur la langue française. Paris: Editions Sociales.

Di Meola, Claudio

1994 Kommen und gehen: eine kognitiv-linguistische Untersuchung der Polysemie deiktischer Bewegungsverben. Tübingen:

Dittmar, Norbert Niemeyer.

1997 Grundlagen der Soziolinguistik. Ein Arbeitsbuch mit Aufgaben. Tübingen: Niemeyer.

Dupré, Paul

1972 Encyclopédie du bon français dans l'usage contemporain: difficultés, subtilités, complexités, singularités. Paris: Editions de Trévise.

Eisenberg, Peter, Hermann Gelhaus, Helmut Henne, Horst Sitta and Hans Wellmann

1998 Duden Grammatik. 6. Auflage. Mannheim/Leipzig/Wien/Zürich: Dudenverlag.

Ferguson, Charles A.

1959 Diglossia. Word 15: 325-340.

Frei, Gertrud

1970 Walserdeutsch in Saley. Bern/Stuttgart: Paul Haupt.

Givón, Talmy

1979 On Understanding Grammar. New York: Academic Press.

Haas, Walter

2000 Die deutschsprachige Schweiz. In: Hans Bickel and Robert Schläpfer, Die viersprachige Schweiz. 2., neu bearbeitete Auflage, 57-138. Aarau: Sauerländer.

Harnisch, Karl-Rüdiger

1982 Doppelpartikelverben als Gegenstand der Wortbildungslehre und Richtungsadverbien als Präpositionen. Ein syntaktischer Versuch. In: Ludwig Eichinger (ed.), Tendenzen verbaler Wortbildung in der deutschen Gegenwartssprache, 107-133. Hamburg: Buske.

Koch, Peter and Wulf Oesterreicher

1985 Sprache der Nähe - Sprache der Distanz: Mündlichkeit und Schriftlichkeit im Spannungsfeld von Sprachtheorie und Sprachgeschichte. Romanistisches Jahrbuch 36: 15-43.

1990 Gesprochene Sprache in der Romania: Französisch, Italienisch, Spanisch. Tübingen: Niemeyer.

1994-96 Funktionale Aspekte der Schriftkultur. In: Hartmut Günther and Otto Ludwig (eds.), Writing and its Use: An Interdisciplinary Handbook of International Research, 587-604. Berlin/New York: de Gruyter.

Levinson, Stephen C.

1996 Language and space. Annual Review of Anthropology 25: 353-382.

Mayer, Mercer

1969 Frog, Where Are You? New York: Dial Press.

McIntyre, Andrew

2001 German Double Particles as Preverbs. Morphology and Conceptual Semantics. Tübingen: Stauffenburg Verlag.

Newman, John

2002 The Linguistics of Sitting, Standing and Lying. Amsterdam: Benjamins.

Olsen, Susan

1996 Pleonastische Direktionale. In: Gisela Harras and Manfred Bierwisch (eds.), Wenn die Semantik arbeitet: Klaus Baumgärtner zum 65. Geburtstag, 303-328. Tübingen: Niemeyer.

Oesterreicher, Wulf

2001 Historiziät - Sprachvariation, Sprachverschiedenheit, Sprachwandel. In: Martin Haspelmath, (ed.), Language Typology

Pittner, Karin and Language Universals: An International Handbook, 1554-1595. Berlin/New York: de Gruyter.

1999 Adverbiale im Deutschen. Untersuchungen zu ihrer Stellung und Interpretation. Tübingen: Stauffenburg Verlag.

Rash, Felicity

1998 The German Language in Switzerland: Multilingualism - Diglossia - Variation. Bern: Lang.

Reichmann, Oskar 
2003 Die Entstehung der neuhochdeutschen Schriftsprache: Wo bleiben die Regionen? In: Raphael Berthele, Helen Christen, Sibylle Germann and Ingrid Hove (eds.), Die deutsche Schriftsprache und die Regionen. Entstehungsgeschichtliche Fragen in neuer Sicht, 29-56. Berlin/New York: de Gruyter.

Sinha, Chris and Tanja Kuteva

1995 Distributed spatial semantics. Nordic Journal of Linguistics 18: 167-199.

Slobin, Dan I.

1991 Learning to think for speaking. Native language, cognition, and rhetorical style. Pragmatics 1: 7-26.

1996 Two ways to travel: Verbs of motion in English and Spanish. In: Sandra A. Thompson and Masayoshi Shibatani (eds.), Grammatical Constructions: Their Form and Meaning, 195-217. Oxford: Oxford University Press.

forthc. The many ways to search for a frog. Linguistic typology and the expression of motion events. In: Sven Strömqvist and Ludo Verhoeven (eds.), Relating Events in Narrative: Typological and Contextual Perspectives. Mahwah, NJ: Lawrence Erlbaum Associates.

Slobin, Dan I. and Aura Bocaz

1988 Learning to talk about movement through time and space: The development of narrative abilities in Spanish and English. Lenguas Modernas 15: 5-24.

Stadelmann, Manfred

1978 Orts- und Richtungsadverbien bei Siedlungsbezeichnungen. Verbreitung und Funktion in oberdeutschen Mundarten untersucht an Tonbandaufnahmen und Erhebungen der Tübinger Arbeitsstelle. Tübingen: Niemeyer.

Staub, Friedrich and Ludwig Tobler (eds.)

1881- Schweizerisches Idiotikon: Wörterbuch der schweizerdeutschen Sprache. Frauenfeld: Huber.

Stein, Dieter

1997 Syntax and varieties. In: Jennifer Cheshire and Dieter Stein (eds.), Taming the Vernacular: From Dialect to Written Standard Language, 35-50. London/New York: Longman.

Strömqvist, Sven and Ludo Verhoeven (eds.)

forthc. Relating Events in Narrative: Typological and Contextual Perspectives. Mahwah, NJ: Lawrence Erlbaum Associates.

Talmy, Leonard

1985 Lexicalization patterns: Semantic structure in lexical forms. In: Timothy Shopen (ed.), Language Typology and Syntactic Description, Volume III: Grammatical Categories and the Lexicon, 57-149. Cambridge/London: Cambridge University Press.

2000a Toward a Cognitive Semantics, Volume I: Concept Structuring Systems. Cambridge, MA/London: MIT Press.

2000b Toward a Cognitive Semantics, Volume II: Typology and Process in Concept Structuring. Cambridge, MA/London: MIT Press.

Tesnière, Lucien

1959 Éléments de syntaxe structurale. Paris: Klincksieck.

Wälchli, Bernhard

2001 A typology of displacement (with special reference to Latvian). Sprachtypologie und Universalienforschung 54: 298-323. 